\title{
Maintenance Problem Identified
}

National Cancer Institute

\section{Source}

National Cancer Institute. Maintenance Problem Identified. NCI Thesaurus. Code C92075.

A device malfunction or problem that occurs after production because the device was not properly maintained according to the instructions (e.g. maintenance may be performed by user facility, distributor, or service provider). 